Proceedings

\title{
Avocado-Derived Biomass: Chemical Composition and Antioxidant Potential ${ }^{+}$
}

\author{
Minerva C. García-Vargas 1,*,,, María del Mar Contreras 2,*,t, Irene Gómez-Cruz ${ }^{2}$, \\ Juan Miguel Romero-García ${ }^{2}$ and Eulogio Castro ${ }^{2}$ \\ 1 Tecnológico Nacional de México/Instituto Tecnológico de Zitácuaro, 61534 Zitácuaro, Mexico \\ 2 Department of Chemical, Environmental and Materials Engineering, Universidad de Jaén, 23071 Jaén, Spain; \\ igcruz@ujaen.es (I.G.-C.); jrgarcia@ujaen.es (J.M.R.-G.); ecastro@ujaen.es (E.C.) \\ * Correspondence: minerva.gv@zitacuaro.tecnm.mx (M.C.G.-V.); mcgamez@ujaen.es or \\ mmcontreras@ugr.es (M.d.M.C.) \\ + Presented at the 1st International Electronic Conference on Food Science and Functional Foods, \\ 10-25 November 2020; Available online: https://foods_2020.sciforum.net/. \\ $\ddagger$ These authors contributed equally to this work.
}

Citation: García-Vargas, M.C.;

Contreras, M.d.M.; Gómez-Cruz, I.; Romero-García, J.M.; Castro, E. Avocado-Derived Biomass:

Chemical Composition and Antioxidant Potential. Proceedings 2021, 70, 100. https://doi.org/10.3390/ foods_2020-07750

Published: 10 November 2020

Publisher's Note: MDPI stays neutral with regard to jurisdictional claims in published maps and institutional affiliations.

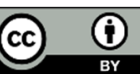

Copyright: (C) 2020 by the authors. Licensee MDPI, Basel, Switzerland. This article is an open access article distributed under the terms and conditions of the Creative Commons Attribution (CC BY) license (http://creativecommons.org/licenses /by/4.0/).

\begin{abstract}
Avocado has become fashionable due to its great organoleptic and nutritional properties. It is consumed as a fresh product and it is also processed to obtain salad oil and guacamole. In all cases, the only usable portion is the pulp. Therefore, to be a more sustainable and profitable agribusiness, it is important to recognize which compounds from the peel and the stone waste can be converted into valuable bio-products. Therefore, their chemical composition was determined according to the National Renewable Energy Laboratory, the total phenolic content by the Folin-Ciocalteu method and the antioxidant properties by the FRAP and TEAC assays. The main components of the peel and stone were acid-insoluble lignin (35.0\% and $15.3 \%$, respectively), polymeric sugars $(23.6 \%$ and $43.9 \%$, respectively), and the aqueous extractives $(15.5 \%$ and $16.9 \%$, respectively). Both biomasses contain lipids and protein, but a minor proportion $(<6 \%)$. The valorization of lignin and sugars is of interest given the high content; stones are a rich source of glucose (93.2\% of the polymeric fraction), which could be used to obtain biofuels or derivatives of interest. The extractive fraction of the peel contained the highest number of phenolic compounds $(4.7 \mathrm{~g} / 100$ g biomass), mainly concentrated in the aqueous fraction (i.e., 87\%) compared to the ethanol one, which was subsequently extracted. It correlated with major antioxidant activity and, therefore, the peel can be applied to obtain antioxidants and water can be used as an environmentally friendly extraction solvent.
\end{abstract}

Keywords: agro-industrial residue valorization; avocado; peel; stone; natural antioxidants; polymeric sugars

\section{Introduction}

Avocado is one of the most commercial fruits, due to its organoleptic properties. Based on average production between 1994 and 2018, the top 10 avocado producing countries were México, followed by the Dominican Republic, Indonesia, Colombia, United States, Peru, Brazil, Chile, Kenya and China. In 2018 the production was around 6.4 million tons worldwide, of which these countries produced $77.4 \%$ [1].

An avocado fruit consists of pulp (65-72\%), stone (20-21\%) and peel (7-15\%) [2,3]. The only usable portion is the pulp, which is consumed fresh or in forms such as halves and frozen cubes [4]. Other processed products are also obtained from avocado such as guacamole, oil, jams, candies juice, ice cream, or as a sauce like dips, chutney, sandwich spreads, mayonnaise, etc. The industrialization around avocado gives as a result a huge amount of waste, for every $1000 \mathrm{~kg}$ of avocado processed, only around $78 \mathrm{~kg}$ or $85 \mathrm{~L}$ of 
cold pressed avocado oil are produced [5], so that tropical fruit can be better exploited if the residual parts are used as alternative source of value-added compounds, with different industrial purposes. This includes natural antioxidants such as phenolic compounds, because consumers prefer products that contain few or no synthetic compounds. Therefore, to enable a complete valorization of avocado peel and stone in multiple bioproducts, the chemical composition was determined and their phenolic content and antioxidant activity were studied.

\section{Methods}

\subsection{Raw Material}

Avocado waste was obtained from the ripe fruit (cultivar 'Hass') bought in a local supermarket (Jaén, Spain). The fruit contained $12.9 \%$ of peel and $13.8 \%$ of stone with moisture of $71 \%$ and $52 \%$, respectively, determined on a fresh weight basis. The peel and stone were dried at room temperature and protected from sunlight and then exposed to a first grinding $(4.0 \mathrm{~mm}$ ) in Retsch SM 100 Mill (Hann, Germany) and to a second grinding $(1.0 \mathrm{~mm})$ in Retsch ZM 200 Mill (Hann, Germany).

\subsection{Extraction and Chemical Characterization}

The extraction and characterization methods are summarized in Figure 1. The air-dried byproducts were characterized in terms of moisture $\left(105^{\circ} \mathrm{C}, 24 \mathrm{~h}\right)$ and ash $(575$ $\left.{ }^{\circ} \mathrm{C}, 4 \mathrm{~h}\right)$ [6]. The elemental analysis ( $\mathrm{H}, \mathrm{C}, \mathrm{N}$, and S) was determined with a TruSpec Micro, Leco (St. Joseph, MI, USA). The O content was estimated by difference, considering the percentages of $\mathrm{H}, \mathrm{C}, \mathrm{N}, \mathrm{S}$ and ash. The protein content was estimated from the $\mathrm{N}$ content and by applying a conversion factor of 6.25 .

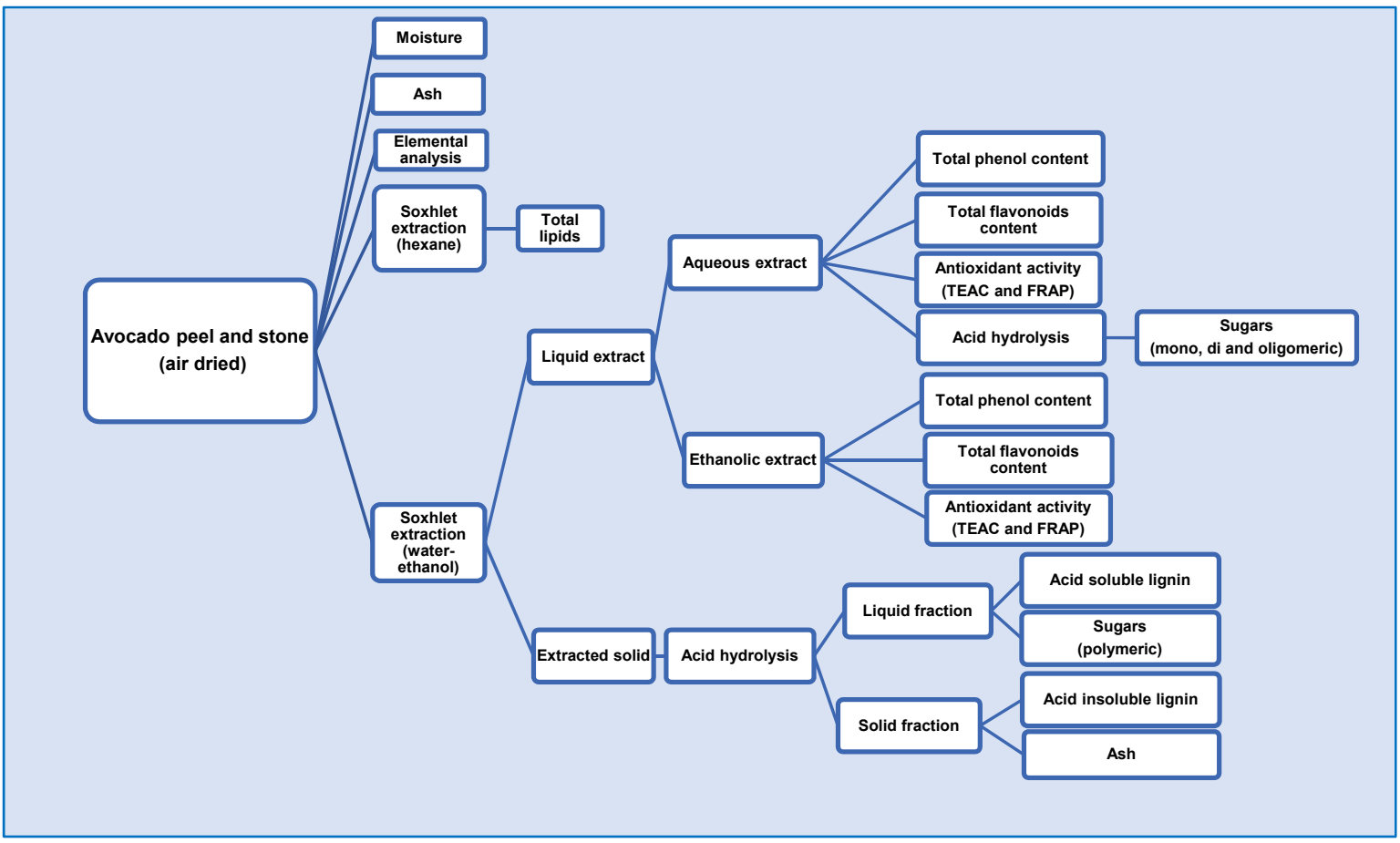

Figure 1. Avocado peel and stone characterization.

Aqueous and ethanolic extracts were obtained using Soxhlet extraction according to the National Renewable Energy Laboratory (NREL) methodology [7], which is based in two consecutive extraction steps, firstly with water and then with ethanol, for $24 \mathrm{~h}$ each step. After the evaporation of the solvent, the yield of the extracts was estimated and referred to the mass of peel and stone loaded in the thimble. Also, the aqueous extract was 
subjected to acid hydrolysis to measure sugars by high-performance liquid chromatography (HPLC) (1200 series) connected with a refractive index detector from Agilent Technologies (Palo Alto, CA, USA). An ICSep ICE-COREGEL 87 H3 column (Transgenomic, Inc., Omaha, NE, USA) was used set at $65{ }^{\circ} \mathrm{C}$ and the mobile phase was $5 \mathrm{mM}$ sulfuric acid at $0.6 \mathrm{~mL} / \mathrm{min}$.

Then, lignin and carbohydrates were determined in the remaining solid fraction via two-step acid hydrolysis [7]. Briefly, $\mathrm{H}_{2} \mathrm{SO}_{4}(72 \%$ w/w) was added to the samples and the mixture placed in a water bath $\left(30^{\circ} \mathrm{C}\right)$ for $1 \mathrm{~h}$. Later, water was added to dilute acid solution to $4 \%$ and to boil the samples for $1 \mathrm{~h}$ at $120{ }^{\circ} \mathrm{C}$. This fractionates lignin into acid insoluble material and acid soluble material. The former is determined gravimetrically and the latter spectrophotometrically at $205 \mathrm{~nm}$ using a coefficient of extinction of $110 \mathrm{~L} / \mathrm{g}$ $\mathrm{cm}$. Moreover, during hydrolysis the polymeric carbohydrates are hydrolyzed into the monomeric forms, which are soluble in the hydrolysis liquid. They were then measured by HPLC using a 2695 liquid chromatographer from Waters (Milford, MA, USA) with refractive index detector and a CARBOSepCHO-782Pb (Transgenomic, Inc., Omaha, NE, USA) column. Ultra-pure water was used as eluent at a flow rate of $0.6 \mathrm{~mL} / \mathrm{min}$ and a column temperature of $70^{\circ} \mathrm{C}$.

In addition, the lipid fraction was extracted using $190 \mathrm{~mL}$ of hexane recycling over 5 $\mathrm{g}$ of sample in a Soxhlet apparatus for $6 \mathrm{~h} \mathrm{[8]}$. Then, the solvent was removed at $60^{\circ} \mathrm{C}$ and the yield was determined as a percent of the mass of extracted lipid to the mass of peel and stone loaded in the thimble.

\subsection{Total Phenolic Content (TPC)}

The TPC was measured using the Folin-Ciocalteu colorimetric method, according to Lama-Muñoz [9], with some modifications. In brief, $0.02 \mathrm{~mL}$ of samples and $0.08 \mathrm{~mL}$ of $\mathrm{Na}_{2} \mathrm{CO}_{3}(0.7 \mathrm{M})$, with $0.01 \mathrm{~mL}$ of Folin-Ciocalteu reagent $(0.2 \mathrm{M})$ was added. The solution was left at room temperature and its absorbance was measured with a microplate reader (Bio-Rad iMark ${ }^{\mathrm{TM}}$, Hercules, CA, USA) at $655 \mathrm{~nm}$. The TPC was reported as g gallic acid equivalents (GAE)/100 $\mathrm{g}$ by using a gallic acid calibration curve.

\subsection{Total Flavonoids Content (TFC)}

The TFC was determined using the aluminum chloride colorimetric method [9]. Next, $1 \mathrm{~mL}$ of extract (adequately diluted) was mixed with $0.03 \mathrm{~mL}$ of $5 \% \mathrm{NaNO}_{2}$, after 5 min $0.03 \mathrm{~mL}$ of $10 \% \mathrm{AlCl}_{3}$ was added and mixed, $6 \mathrm{~min}$ later the extracts were neutralized with $2 \mathrm{~mL}$ of $1 \mathrm{~N} \mathrm{NaOH}$, and incubated for $5 \mathrm{~min}$ at room temperature in the dark. Absorbance was measured with the aforementioned microplate reader at $510 \mathrm{~nm}$. The total flavonoid content was calculated from a calibration curve build with rutin, and the results were expressed as g rutin equivalents (RE) per $100 \mathrm{~g}$.

\subsection{Antioxidant Activity}

The antioxidant activity was appraised by measuring the ability of the antioxidants

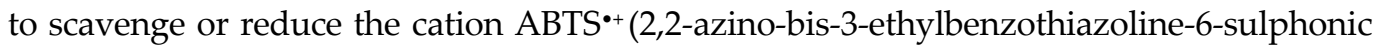
acid) and $\mathrm{Fe}^{3+}$ using the Trolox equivalent antioxidant capacity (TEAC) and ferric ion reducing antioxidant power (FRAP) assays, respectively, according to Medfai et al. [10]. The absorbance was measured with Bio-Rad iMark ${ }^{\mathrm{TM}}$ at $734 \mathrm{~nm}$ for TEAC and $593 \mathrm{~nm}$ for FRAP. Absorbance readings of the antioxidant extracts were compared to standard calibration curves of the hydrophilic vitamin E analog, Trolox $(6-330 \mu \mathrm{M})$, and the results were expressed as mmol Trolox equivalents (TE) per $100 \mathrm{~g}$. 


\section{Results and Discussion}

\subsection{Chemical Characterization of Avocado Waste}

The avocado peel and stone presented similar elemental composition but the peel contained slightly higher percentages of nitrogen and oxygen (Table 1). The results of the stone agreed with the study by Perea-Moreno [11]. It showed a similar composition to that of olive stone and almond shell, two byproducts commonly used as biofuel for heating. As these authors highlighted, the avocado stone has a potential for this use but from an industrial point of view some drawbacks are the ash content and the humidity, which are higher than those reported in the reference materials. Sulfur was not detected and so the formation of $\mathrm{SO}_{x}$ can be diminished. Similar attention can be given to the avocado peel (Figure 1, Table 1). Therefore, obtaining valuable compounds before burning could be profitable to provide another value to this waste.

Table 1. Elemental composition of avocado peel and stone.

\begin{tabular}{cccccc}
\hline Element $^{\mathbf{1}} \mathbf{( \% )}$ & Peel & Stone & Element $^{{ }^{\mathbf{~}} \mathbf{( \% )}}$ & Peel & Stone \\
\hline $\mathrm{N}$ & $0.97 \pm 0.07$ & $0.66 \pm 0.01$ & $\mathrm{H}$ & $5.71 \pm 0.02$ & $5.58 \pm 0.02$ \\
$\mathrm{C}$ & $49.83 \pm 0.42$ & $42.05 \pm 0.05$ & $\mathrm{O}$ & $42.2 \pm 2.62$ & $50.79 \pm 1.56$ \\
Ash & $3.81 \pm 0.05$ & $2.76 \pm 0.28$ & Humidity & $70.9 \pm 0.2$ & $52.0 \pm 0.4$ \\
\hline
\end{tabular}

${ }^{1} \mathrm{~S}$ was not detected.

The chemical composition of avocado waste is shown in Figure 2. In general, both biomasses showed higher differences in the polymeric glucose content and acid insoluble lignin; the former was the highest component in the avocado stone and the latter in the avocado peel.

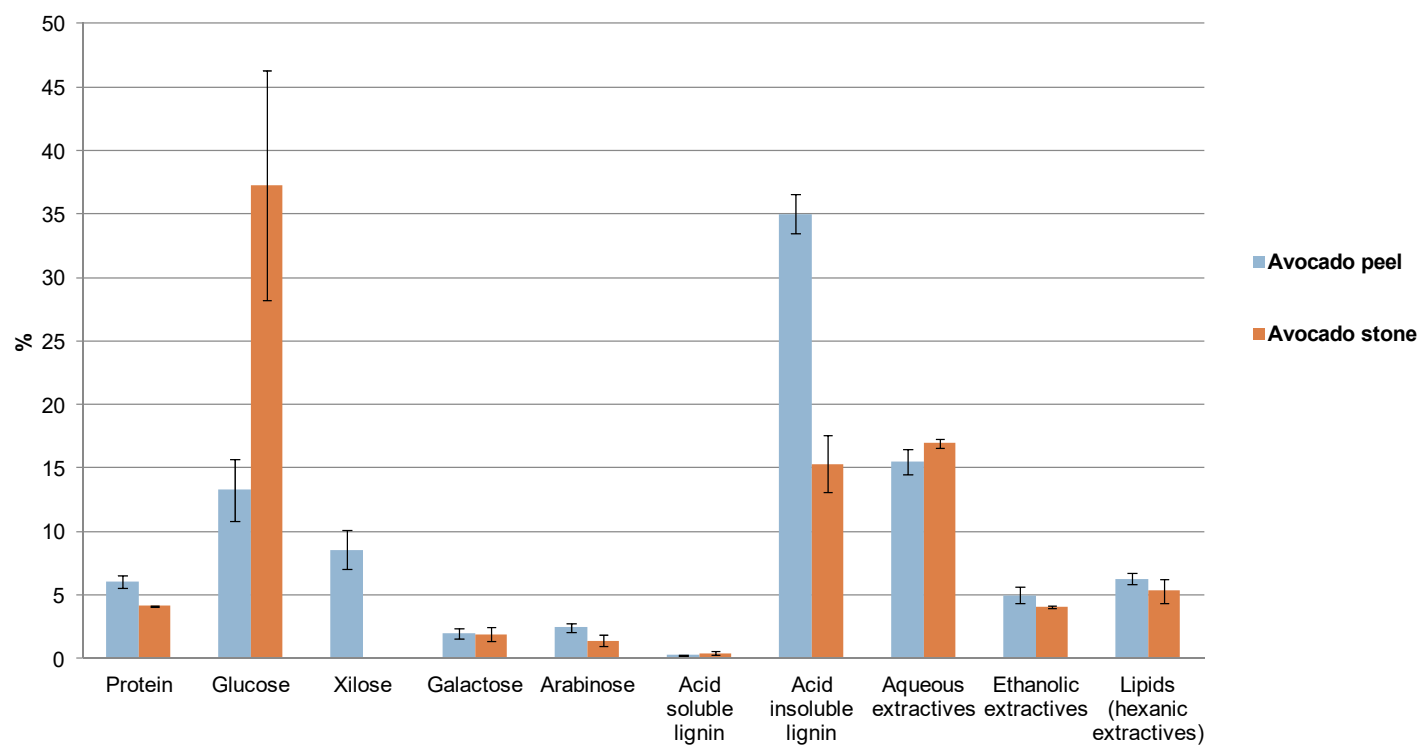

Figure 2. Chemical composition of the avocado peel and stone.

Therefore, the valorization of lignin and sugars is of interest given the high content, which could be used to obtain biofuels or derivatives of interest, such as aromatic compounds, furans and organic acids. Moreover, in terms of content, another interesting fraction was the extractive fraction, which contains non-structural components. The aqueous fraction was $15.5 \%$ and $16.9 \%$ of the peel and stone, respectively. It contained monomeric sugars, which was $15.0 \%$ and $72.5 \%$ of the aforementioned amount, respectively. 


\subsection{TPC, TFC and Antioxidant Activity}

The extractive fraction also presents other non-structural components such as phenolic compounds. In avocado waste the content of this fraction was high, as commented before (Figure 2). Therefore, as a preliminary way to know the potential of avocado waste to obtain antioxidants, the TPC, TFC and the antioxidant activity were determined in the aqueous and ethanolic extracts obtained by the Soxhlet extraction. As Table 2 shows, the extractive fraction of the peel contained the highest amount of phenolic compounds (4.7 $\mathrm{g} / 100 \mathrm{~g}$ biomass), mainly concentrated in the aqueous fraction (i.e., $87 \%$ ) compared to the ethanol one, which was subsequently extracted. It correlated with major antioxidant activity and therefore the peel can be applied to obtain antioxidants and water can be used as an environmentally friendly extraction solvent.

The TPC found for avocado peel in the present study is within the range reported in the consulted literature, which goes between 2.0 and $10.7 \mathrm{~g}$ GAE/100 $\mathrm{g}$ of avocado waste [12]. Alternatively, the aqueous extracts obtained here from the peel were richer in phenolic compounds compared to those found in literature (values up to $9.0 \mathrm{~g} \mathrm{GAE} / 100 \mathrm{~g}$ ) [13]; also, the antioxidant activity was higher. The difference in the values is attributed to the different pre-treatments, type of extractions, and solvents used, and in addition, place of origin and degree of maturity of the avocado, among other things.

Table 2. Total phenolic content (TPC), total flavonoids content (TFC) and antioxidant activity determined by TEAC and FRAP assays.

\begin{tabular}{|c|c|c|c|c|c|c|c|c|}
\hline \multirow{2}{*}{ Part } & \multicolumn{2}{|c|}{ TPC } & \multicolumn{2}{|c|}{ TFC } & \multicolumn{2}{|c|}{ TEAC } & \multicolumn{2}{|c|}{ FRAP } \\
\hline & $\mathrm{AE}$ & $\mathrm{EE}$ & $\mathrm{AE}$ & EE & $\mathrm{AE}$ & EE & $\mathrm{AE}$ & EE \\
\hline \multicolumn{9}{|c|}{ In terms of biomass weight (g GAE or g rutin or mmol TE/100 g, d.w.) } \\
\hline $\mathrm{AP}$ & $4.13 \pm 0.56$ & $0.60 \pm 0.12$ & $5.35 \pm 1.36$ & $0.75 \pm 0.09$ & $17.48 \pm 3.12$ & $0.47 \pm 0.05$ & $15.20 \pm 2.02$ & $1.49 \pm 0.34$ \\
\hline AS & $0.31 \pm 0.06$ & $0.18 \pm 0.03$ & $0.45 \pm 0.13$ & $0.67 \pm 0.02$ & $1.66 \pm 0.31$ & $0.32 \pm 0.08$ & $1.29 \pm 0.32$ & $0.66 \pm 0.05$ \\
\hline \multicolumn{9}{|c|}{ In terms of extract weight (g GAE or g rutin or mmol TE/100 g, d.w.) } \\
\hline $\mathrm{AP}$ & $26.56 \pm 2.77$ & $12.60 \pm 3.17$ & $34.23 \pm 6.90$ & $15.63 \pm 1.25$ & $112.15 \pm 13.35$ & $9.67 \pm 2.11$ & $97.78 \pm 7.83$ & $37.77 \pm 1.68$ \\
\hline AS & $1.81 \pm 0.34$ & $4.39 \pm 0.88$ & $2.66 \pm 0.82$ & $16.49 \pm 0.80$ & $9.85 \pm 2.03$ & $7.84 \pm 2.04$ & $7.71 \pm 1.93$ & $16.31 \pm 1.62$ \\
\hline
\end{tabular}

$\mathrm{AE}$, aqueous extract; $\mathrm{AP}$, avocado peel; $\mathrm{AS}$, avocado stone; $\mathrm{EE}$, ethanolic extract; GAE, gallic acid equivalents; TE, trolox equivalents.

\section{Conclusions}

The avocado peel and stone have a high potential to exploit various valuable compounds from their chemical composition in a biorefinery context. Particularly, the stone is rich in glucose, mainly from the polymeric fraction and the peel in lignin. In addition, the peel is a rich source of antioxidants and water can be used as an environmentally friendly extraction solvent.

Funding: This research received no external funding.

Institutional Review Board Statement: Not applicable.

Informed Consent Statement: Not applicable.

Data Availability Statement: Data are available on request from the corresponding author.

Acknowledgments: Authors thank the FEDER UJA projects 1260905 funded by "Programa Operativo FEDER 2014-2020" and "Consejería de Economía y Conocimiento de la Junta de Andalucía". I.G.-C. expresses her gratitude to the University of Jaén for the grant R5/04/2017 and M.C.G.-V. for the grant "Beca-comisión para estadía técnica del Tecnológico Nacional de México/Instituto Tecnológico de Zitácuaro y Universidad de Jaén".

Conflicts of Interest: The authors declare no conflict of interest. 


\section{References}

1. Food and Agriculture Organization of the United Nations (FAO). FAOSTAT-2020. Available online: http://www.fao.org/faostat/ en/\#data/QC/visualize (accessed on 10 October 2020).

2. Bet, C.D.; Waiga, L.H.; De Oliveira, C.S.; Lacerda, L.G.; Schnitzler, E. Morphological and thermoanalytical study of modified avocado seeds starch with lactic acid. Chem. J. Mold. 2017, 12, 13-18, doi:10.19261/cjm.2017.438.

3. Krumreich, F.D.; Borges, C.D.; Mendonça, C.R.B.; Jansen-Alves, C.; Zambiazi, R.C. Bioactive compounds and quality parameters of avocado oil obtained by different processes. Food Chem. 2018, 257, 376-381, doi:10.1016/j.foodchem.2018.03.048.

4. Barbosa-Martín, E.; Chel-Guerrero, L.; González-Mondragón, E.; Betancur-Ancona, D. Chemical and technological properties of avocado (Persea americana Mill.) seed fibrous residues. Food Bioprod. Process. 2016, 100, 457-463, doi:10.1016/j.fbp.2016.09.006.

5. Permal, R.; Leong Chang, W.; Seale, B.; Hamid, N.; Kam, R. Converting industrial organic waste from the cold-pressed avocado oil production line into a potential food preservative. Food Chem. 2020, 306, 125635, doi:10.1016/j.foodchem.2019.125635.

6. Sluiter, A.; Hames, B.; Ruiz, R.; Scarlata, C.; Sluiter, J.; Templeton, D. Determination of Ash in Biomass; Technical Report NREL/TP-510-42622; Laboratory Analytical Procedure (LAP): Golden, CO, USA, 2008.

7. Sluiter, A.; Hames, B.; Ruiz, R.; Scarlata, C.; Sluiter, J.; Templeton, D.; Crocker, D. Determination of Structural Carbohydrates and Lignin in Biomass. Technical report NREL/TP-510-42618 Analytical Procedure; Laboratory Analytical Procedure (LAP): Golden, CO, USA, 2012.

8. Ferrentino, G.; Ndayishimiye, J.; Haman, N.; Scampicchio, M. Functional activity of oils from brewer's spent grain extracted by supercritical carbon dioxide. Food Bioprocess Technol. 2019, 12, 789-798, doi:10.1007/s11947-019-02249-3.

9. Lama-Muñoz, A.; Contreras, M. del M.; Espínola, F.; Moya, M.; de Torres, A.; Romero, I.; Castro, E. Extraction of oleuropein and luteolin-7-O-glucoside from olive leaves: Optimization of technique and operating conditions. Food Chem. 2019, 293, 161-168, doi:10.1016/j.foodchem.2019.04.075.

10. Medfai, W.; Contreras, M. del M.; Lama-Muñoz, A.; Mhamdi, R.; Oueslati, I.; Castro, E. How cultivar and extraction conditions affect antioxidants type and extractability for olive leaves valorization. ACS Sustain. Chem. Eng. 2020, 8, 5107-5118, doi:10.1021/acssuschemeng.9b07175.

11. Perea-Moreno, A.J.; Aguilera-Ureña, M.J.; Manzano-Agugliaro, F. Fuel properties of avocado stone. Fuel 2016, 186, 358-364, doi:10.1016/j.fuel.2016.08.101.

12. Páramos, P.R.S.; Granjo, J.F.O.; Corazza, M.L.; Matos, H.A. Extraction of high value products from avocado waste biomass. J. Supercrit. Fluids 2020, 165, 104988, doi:10.1016/j.supflu.2020.104988.

13. Saavedra, J.; Córdova, A.; Navarro, R.; Díaz-Calderón, P.; Fuentealba, C.; Astudillo-Castro, C.; Toledo, L.; Enrione, J.; Galvez, L. Industrial avocado waste: Functional compounds preservation by convective drying process. J. Food Eng. 2017, 198, 81-90, doi:10.1016/j.jfoodeng.2016.11.018. 